\title{
Stimulation of pituitary and testicular functions with LH-RH agonist or pulsatile LH-RH treatment in the rhesus monkey during the non-breeding season
}

\author{
E. J. Wickings, P. Zaidi, G. Brabant and E. Nieschlag \\ Max-Planck-Clinical Research Unit for Reproductive Medicine and Department of \\ Experimental Endocrinology, University Women's Hospital, Westring 11, D-4400 Münster, \\ West Germany
}

\begin{abstract}
Summary. Out-of-season male rhesus monkeys were used to compare the effectiveness of pulsatile treatment with $\mathrm{LH}-\mathrm{RH}$ and administration of LH-RH agonist on testicular function.

Treatment with LH-RH agonist (1.0 $\mu \mathrm{g}$ Hoe 766/day) for 11 weeks resulted in partial stimulation of pituitary and testicular functions. The pituitary LH response to the agonist increased during treatment. Testosterone levels were stimulated to within the normal range and 2 of the 4 treated monkeys produced ejaculates, but sperm counts were below normal.

Pulsatile treatment with LH-RH (100 ng every 96 min for 7 days alternating with LH-RH agonist treatment for 7 days) in 2 monkeys induced full testicular activity after 7 weeks. Ejaculations were induced at a time when the rhesus monkey is normally sexually inactive. Seminal characteristics at the end of treatment were similar to values in the normal breeding season. In samples collected from one monkey over a 24 -h period before treatment there were no LH spikes and very low testosterone levels. During pulsatile LH-RH treatment distinct LH and testosterone spikes occurred, comparable to those in the breeding season.
\end{abstract}

\section{Introduction}

In man and female rhesus monkeys pulsatile $\mathrm{LH}$ secretion is required for normal gonadal function (Dierschke, Bhattacharya, Atkinson \& Knobil, 1970; Yen, Tsai, Naftolin, Vandenbergh \& Ajabor, 1972; Naftolin, Judd \& Yen, 1973; Rowe, Racey, Lincoln, Ellwood, Lehane \& Shenton, 1975; Rubin, Gouin, Lubin, Poland \& Pirke, 1975) and is, in turn, dependent, at least in the female, on the pulsatile release of LH-RH from the hypothalamus (Carmel, Araki \& Ferin, 1976; Antunes, Carmel, Housepian \& Ferin, 1978). Following the recent development of accurate portable infusion pumps for the pulsatile administration of releasing hormone over prolonged periods, such treatment with "hypothalamic prostheses" (Knobil, 1980) has been shown to be effective in inducing ovulation in hypothalamic-lesioned and infantile rhesus monkeys (Knobil, Plant, Wildt, Belchetz \& Marshall, 1980; Wildt, Marshall \& Knobil, 1980) and in women with hypothalamic amenorrhoea (Leyendecker, Struve \& Plotz, 1980). Pulsatile LH-RH application was also capable of inducing testicular function in rams during the nonbreeding season (Lincoln, 1979) and in boys with delayed puberty (Jacobson, Seyler, Tamborlane, Gertner \& Genel, 1979). 
However, pulsatile replacement of LH-RH has practical limitations in routine use, requiring intensive observation of the patient. Appropriate daily administration of LH-RH or a long-acting agonist of LH-RH would offer a practical alternative approach, and some successes have been achieved in the treatment of male infertility (Aparicio et al., 1976) and hypogonadotrophic hypogonadism (Mortimer, McNeilly, Fisher, Murray \& Besser, 1974; Smith, Donald, Espiner \& Stronach, 1979). Of the reported failures, some at least can be explained by an overdosage of the hormone or agonist, resulting in a down-regulation of pituitary and testicular receptors (Smith et al., 1979).

We have therefore compared the effects of pulsatile LH-RH replacement with those of low-dose, intermittent LH-RH agonist treatment on pituitary and testicular functions of the male rhesus monkey. During the non-breeding season, these monkeys can be considered as equivalent to men with hypogonadotrophic hypogonadism resulting from decreased hypothalamic function (Wickings \& Nieschlag, 1980a).

\section{Materials and Methods}

Animals. Six male adult rhesus monkeys (body weight $7.4-11.0 \mathrm{~kg}$ ) were used. They were housed under controlled conditions of temperature, humidity and lighting (12 h light from 06:00 $\mathrm{h} / 24 \mathrm{~h}$ ), without any contact with female monkeys. Basal blood samples were collected under ketamine hydrochloride anaesthesia (Vetalar: Parke-Davis, Freiburg; $8-12 \mathrm{mg} / \mathrm{kg}$ ) from a cubital vein. The serum obtained was stored at $-20^{\circ} \mathrm{C}$ until analysis. For acute stimulation tests with LH-RH and the agonist, further injections of ketamine were given as required (8-12 $\mathrm{mg} / \mathrm{kg} / \mathrm{h}$ ).

Methods. Serum testosterone concentrations were measured by radioimmunoassay following ether extraction (Nieschlag \& Loriaux, 1972). The intra- and inter-assay coefficients of variation were 2.9 and $9.1 \%$ respectively, and the sensitivity of the assay was $25 \mathrm{pg}$. Serum prolactin levels were measured using commercially available reagents (Isotopen-Dienst West, Dreieich), for which complete cross-reactivity with rhesus prolactin has been demonstrated (Wickings \& Nieschlag, 1980b). The intra- and inter-assay variations were 3.4 and $9.4 \%$ respectively, and the sensitivity of the assay was $25 \mu \mathrm{i} . \mathrm{u} . / \mathrm{ml}$. Serum concentrations of LH were determined by an in-vitro bioassay using a mouse Leydig cell suspension and MRC 69/104 as the LH standard preparation (Wickings, Quazi \& Nieschlag, 1979). The intra-assay variation was $8.7 \%$, the between-assay variation was $10.4 \%$ and the sensitivity of the assay was $1.5 \mathrm{mi} . \mathrm{u} . / \mathrm{ml}$.

Conscious monkeys were electroejaculated by applying both electrodes to the penis, according to the method of Mastroianni \& Manson (1963). The evaluation of seminal parameters was carried out as described previously (Wickings \& Nieschlag, 1980a). The frequency of spontaneous ejaculation was calculated from the number of ejaculatory plugs found under the monkeys' cages each morning. Testicular volumes were calculated from measurements of the length and width of the testes in the scrotum, assuming the testes to be regular ellipsoids.

Pituitary stimulation tests with LH-RH. Tests were performed on 3 occasions during the year for 4 monkeys before they received the agonist treatment. The tests were carried out during the non-breeding season (April-May), when the testes were redeveloping (August-September) and during the breeding season (October), as defined for our rhesus monkeys (Wickings \& Nieschlag, 1980a). Following collection of a basal blood sample, LH-RH (Relefact: Hoechst AG, Frankfurt; $50 \mu \mathrm{g}$ i.v.) was injected and 2 further blood samples were collected at 30 and 60 $\min$. $\mathrm{LH}$ and testosterone concentrations were measured in each sample.

Administration of a low dose of LH-RH agonist. Treatment was carried out between April and June of the following year in 4 rhesus monkeys. Each received 1.0 $\mu \mathrm{g} \mathrm{LH}-\mathrm{RH}$ agonist (D-Ser(TBu) ${ }^{6}$-LH-RH-ethylamide: Hoe 766, Hoechst AG, Frankfurt) s.c. daily for 5 days per 
week for two 5-week periods separated by 1 week without treatment. This intermittent administration of the agonist was designed so that the low physiological doses used avoided any chronic overstimulation of the pituitary, which would result in a down-regulation of the testicular $\mathrm{LH} / \mathrm{hCG}$ receptors, but consistently produced an acute release of $\mathrm{LH}$ when given daily for extended periods (Sandow, von Rechenberg, Baeder \& Engelbart, 1980). Electroejaculation was attempted before and after treatment, and acute pituitary stimulation tests were performed with the agonist $(1.0 \mu \mathrm{g}$, i.v.) before, during and after treatment, as described for the LH-RH tests. Serum LH, prolactin and testosterone concentrations were monitored at weekly intervals, blood samples being collected between 08:00 and 10:00 h, $24 \mathrm{~h}$ after the injection of the agonist.

Pulsatile administration of $L H-R H$. Two monkeys received pulsatile LH-RH treatment (100 ng s.c. every $96 \mathrm{~min}$ for 1 week) alternated with LH-RH agonist treatment (100 ng s.c. per day for 1 week) for a period of 7 weeks from the beginning of April. The monkeys were placed in primate chairs for the LH-RH administration and synthetic LH-RH was given via a portable pump (Auto-Syringe Model AS2C, Hooksett, New Hampshire, U.S.A.) set to deliver $50 \mu \mathrm{l}$ in 15 sec every $96 \mathrm{~min}$. This alternating dose regimen was chosen because in our experience longer periods of chair restraint affect the physical well-being of the animal.

Before commencing treatment and on the last day of LH-RH pulsing, blood samples were collected every $20 \mathrm{~min}$ for $24 \mathrm{~h}$ from one monkey via an indwelling venous catheter without anaesthesia. In addition, during pulsatile LH-RH treatment blood samples were collected twice weekly between 10:00 and 12:00 h immediately before a pulse.

Statistics. Student's paired $t$ test was used to evaluate the response to the different tests performed and to compare changes in results during the treatment period in individual animals. The unpaired $t$ test was used to compare values from the experimental animals used in this study with the control data from our troop.

\section{Results}

\section{Administration of low doses of LH-RH agonist}

The results of treatment for 4 monkeys over 11 weeks are shown in Text-fig. 1. Normal data from this rhesus colony (Wickings \& Nieschlag, 1980a) have been included for comparison. Serum LH levels were not different from normal out-of-season values. Concentrations at the end of treatment were still lower than corresponding breeding season values $(60.8 \pm 18.0$ mi.u./ $\mathrm{ml}$; mean \pm 1 s.e.m.; Wickings \& Nieschlag, 1980a). Serum testosterone levels increased during the second period of treatment to reach concentrations similar to those in the breeding season. There was a significant increase in testicular volume during treatment $(P<0.025)$, but the testes remained smaller than those of monkeys in the breeding season $(27.5 \pm 1.5 \mathrm{ml} ; P<0.05)$. Serum prolactin levels decreased significantly $(P<0.0025)$ during the second period of treatment.

None of the monkeys responded to electroejaculation before treatment, whereas ejaculates were obtained from 2 of the 4 monkeys at the end of the treatment period. Sperm counts of 75 and $79 \times 10^{6}$ /ejaculate were recorded, but these were below the normal range for this troop $\left(110-1100 \times 10^{6} /\right.$ ejaculate). Motility (54 and 87\%) and morphology (92 and $90 \%$ normal spermatozoa) in the 2 monkeys were not different from normal values. The frequency of spontaneous ejaculation increased in the treated monkeys, in comparison to observations in 10 control animals in the same colony. Ejaculatory plugs were found 3-4 times more frequently than in untreated monkeys.

The pituitary and testicular responses to an acute challenge with the LH-RH agonist $(1 \mu \mathrm{g}$ i.v.) are summarized in Table 1 . The greatest increase in LH over basal levels was seen after 11 weeks of treatment $(P<0.05$ for the comparison with the value at 0 min at Week 11 and the value at $30 \mathrm{~min}$ at Week 0 ). The testosterone responses were similar on all 3 occasions. The LH 


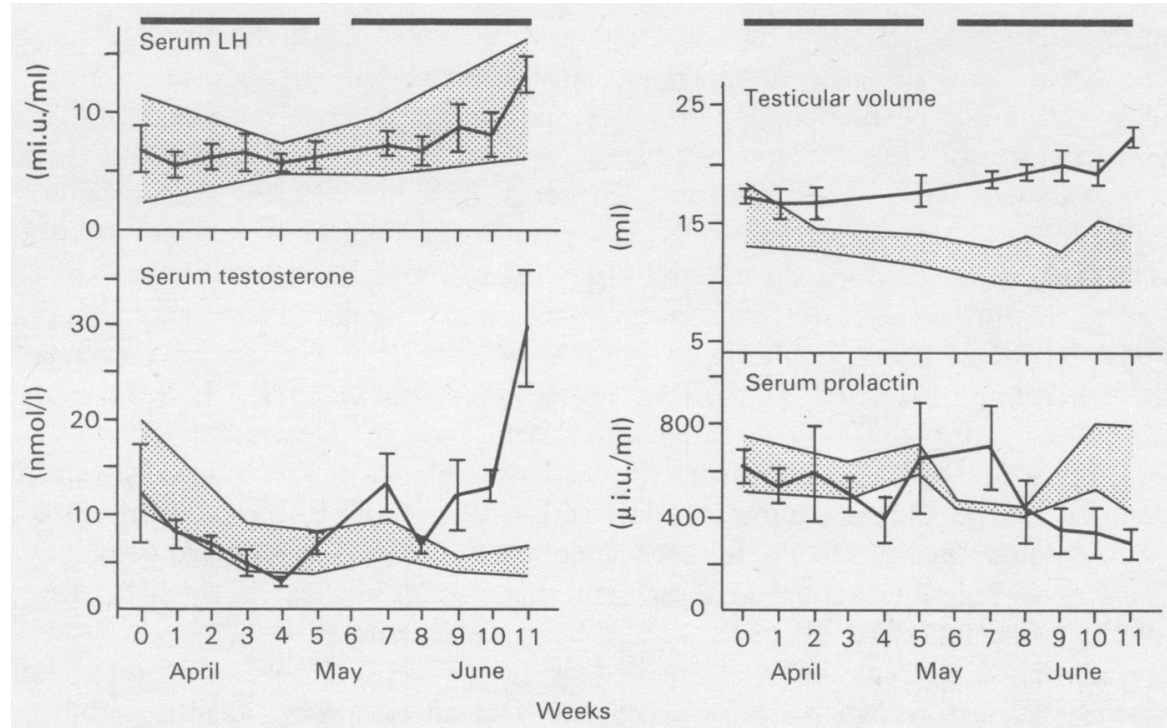

Text-fig. 1. Changes in serum hormones and testicular volume during treatment (horizontal bar) of 4 adult rhesus monkeys during the non-breeding season with $1 \mu \mathrm{g} \mathrm{LH-RH}$ agonist/day (s.c.). The stippled area respresents the normal range for data collected over 5 years in this rhesus colony (Wickings \& Nieschlag, 1980a).

Table 1. Changes in the acute response of serum $\mathrm{LH}$ and testosterone concentrations (mean \pm 1 s.e.m.) to a bolus injection of LH-RH agonist $(1 \mu \mathrm{g}$, i.v. $)$ in 4 male adult rhesus monkeys receiving treatment with the agonist $(1 \mu \mathrm{g} /$ day s.c.) during the non-breeding season

\begin{tabular}{|c|c|c|c|c|c|c|}
\hline & \multicolumn{3}{|c|}{ LH (mi.u./ml) } & \multicolumn{3}{|c|}{ Testosterone (nmol/l) } \\
\hline & $0 \mathrm{~min}$ & $30 \mathrm{~min}$ & $60 \mathrm{~min}$ & $0 \mathrm{~min}$ & $30 \mathrm{~min}$ & $60 \mathrm{~min}$ \\
\hline $\begin{array}{l}\text { Basal } \\
5 \text { weeks } \\
11 \text { weeks }\end{array}$ & $\begin{array}{r}5.2 \pm 2.4 \\
6.9 \pm 0.9 \\
13.3 \pm 1.6\end{array}$ & $\begin{array}{l}24.0 \pm 6.8 \\
20.6 \pm 4.0 \\
50.2 \pm 14.2\end{array}$ & $\begin{array}{l}21.0 \pm 6.2 \\
20.5 \pm 2.4 \\
46.0 \pm 13.8\end{array}$ & $\begin{array}{r}12.5 \pm 3.4 \\
5.5 \pm 0.4 \\
13.0 \pm 4.1\end{array}$ & $\begin{array}{l}33.4 \pm 3.3 \\
22.2 \pm 2.9 \\
31.2 \pm 1.3\end{array}$ & $\begin{array}{l}39.0 \pm 6.2 \\
35.1 \pm 2.6 \\
37.1 \pm 1.5\end{array}$ \\
\hline
\end{tabular}

and testosterone responses to $1 \mu \mathrm{g}$ agonist before treatment were similar to those measured during quiescence in response to injection of LH-RH $(50 \mu \mathrm{g})$ (Table 2), but the increase in the LH-response after agonist treatment was not comparable to that seen during the natural development of pituitary activity in August.

Table 2. The response of serum $\mathrm{LH}$ and testosterone concentrations (mean \pm 1 s.e.m.) to a bolus injections of LH-RH ( $50 \mu \mathrm{g}$, i.v.) in 4 adult rhesus monkeys in tests performed at different times of the year

\begin{tabular}{lccccccc}
\hline & \multicolumn{3}{c}{ LH (mi.u./ml) } & & \multicolumn{3}{c}{ Testosterone (nmol/l) } \\
\cline { 2 - 3 } \cline { 7 - 8 } & $0 \mathrm{~min}$ & $30 \mathrm{~min}$ & $60 \mathrm{~min}$ & & $0 \mathrm{~min}$ & $30 \mathrm{~min}$ & $60 \mathrm{~min}$ \\
\hline $\begin{array}{c}\text { April-May } \\
\text { (quiescence) }\end{array}$ & $4.5 \pm 1.4$ & $16.6 \pm 1.0$ & $16.5 \pm 1.6$ & & $5.5 \pm 0.5$ & $26.7 \pm 3.3$ & $31.0 \pm 2.7$ \\
$\begin{array}{c}\text { August-September } \\
\quad \text { (redevelopment) }\end{array}$ & $18.0 \pm 4.2$ & $262 \pm 40$ & $184 \pm 45$ & & $8.9 \pm 2.0$ & $22.1 \pm 8.6$ & $26.2 \pm 6.9$ \\
$\begin{array}{c}\text { October } \\
\text { (breeding season) }\end{array}$ & $10.0 \pm 7.0$ & $59.2 \pm 12.6$ & $46.0 \pm 13.3$ & & $23.5 \pm 5.8$ & $53.3 \pm 4.0$ & $54.5 \pm 8.7$ \\
\hline
\end{tabular}




\section{Pulsatile LH-RH treatment}

The effects of alternating pulsatile LH-RH and low-dose LH-RH agonist treatment on serum hormone levels and seminal characteristics of the 2 rhesus monkeys treated are shown in Text-fig. 2. Serum LH and testosterone concentrations increased to values normally measured in the breeding season. Testicular volume of Monkey 777 almost doubled (12.0 to $23.0 \mathrm{ml}$ ), but that of Monkey 2892 showed less change $(18.0$ to $23.0 \mathrm{ml}$ ). The frequency of spontaneous ejaculations also increased, and ejaculates could be obtained by electrostimulation after 5 weeks of treatment. Sperm counts fluctuated, but at 7 weeks seminal characteristics in both monkeys were within the normal values for this colony in the breeding season (see above).

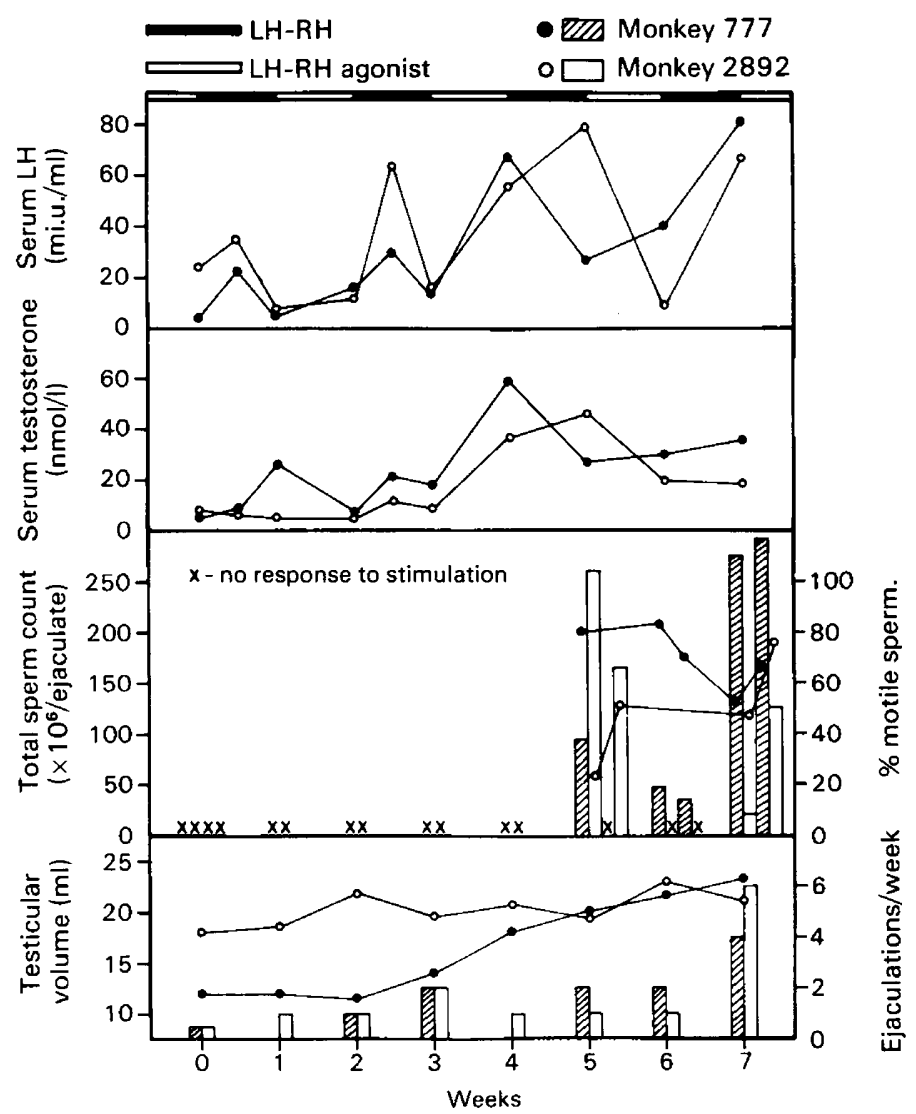

Text-fig. 2. Effects of 7 weeks alternating treatment with pulsatile LH-RH (100 ng every 96 min s.c. for 7 days) and LH-RH agonist (100 ng/day s.c. for 7 days) on pituitary and testicular functions of 2 adult rhesus monkeys during the non-breeding season. Treatment began at the start of April (Week 0). Blood samples were collected either 95 min after the preceding LH-RH pulse, or $24 \mathrm{~h}$ after the last injection of LH-RH agonist.

During the pretreatment 24-h sampling period, no fluctuations in $\mathrm{LH}$ or testosterone were demonstrable in Monkey 777, but 8 distinct LH spikes were identifiable 7 weeks later (Text-fig. 3). Not every LH-RH pulse, however, elicited an LH response, especially not between 15:00 and 23:00 h. Furthermore, not every LH peak was followed by an increase in testosterone, but when LH and testosterone peaks could be correlated $(n=10)$, there was an average lag period of $40 \mathrm{~min}$. 


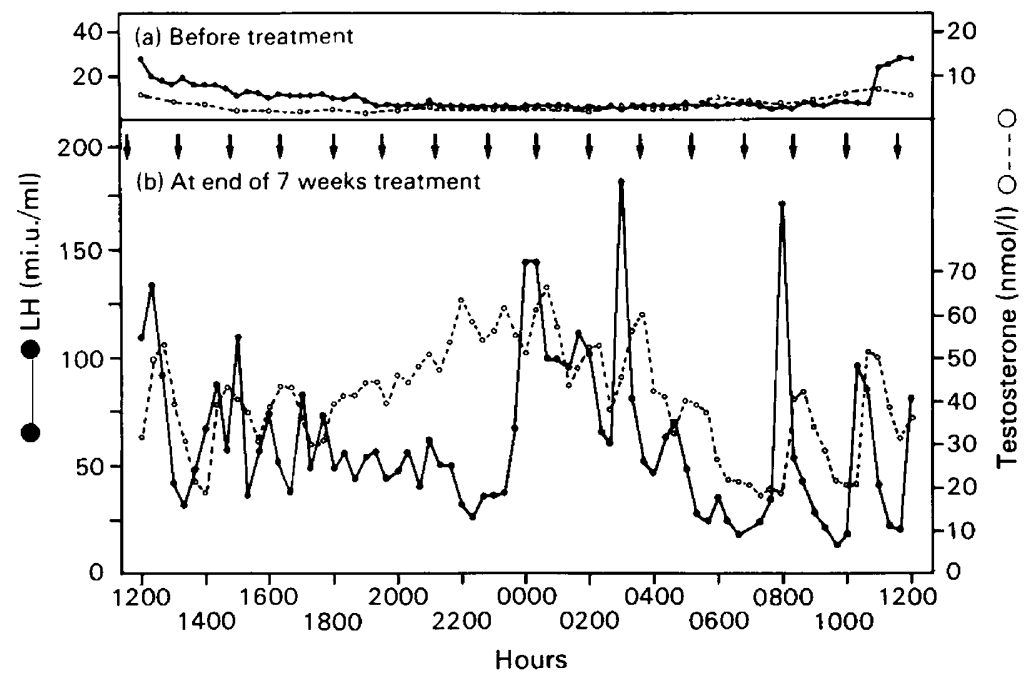

Text-fig. 3. The 24-h patterns of serum $\mathrm{LH}$ and testosterone concentrations in one adult male rhesus monkey (No. 777) (a) before and (b) on the last day of pulsatile LH-RH treatment (100 ng LH-RH every $96 \mathrm{~min}$ s.c.) for 7 weeks during the non-breeding season. Samples were collected every $20 \mathrm{~min}$; the arrows indicate the LH-RH pulses.

\section{Discussion}

The period of sexual quiescence in the rhesus monkey is characterized by reduced pituitary activity, absent or reduced LH-spikes and regressed testicular functions. The pituitary, however, still retains the capacity to respond to LH-RH and the testes, in turn, can be stimulated by the resulting increase in serum LH levels, and also by hCG (Wickings \& Nieschlag, 1980a). During preparations for the breeding season redevelopment of the pituitary-gonadal axis occurs first at the pituitary level, with a marked increase in LH reserves. The testis only demonstrates full activity during the period corresponding to the natural breeding season, when a smaller increment in LH levels, following acute LH-RH stimulation, can elicit a higher testosterone response than that seen during testicular resurgence. This sequence of events has also been demonstrated in other seasonally breeding animals, e.g. ram (Lincoln, Peet \& Cunningham, 1977) and red deer (Lincoln \& Kay, 1979).

This seasonal induction of pituitary and testicular function, most probably the result of increased hypothalamic activity (Knobil, 1980), could not be completely mimicked by daily administration of the LH-RH agonist in the present study. Although some stimulation of endocrine testicular function could be demonstrated, this was not evident from the basal concentrations of LH measured during treatment. These single samples, however, were collected $24 \mathrm{~h}$ after the injection of the LH-RH agonist and cannot reflect the dynamics of the pituitary response to the agonist. The acute stimulation tests revealed that $\mathrm{LH}$ secretion was increased during treatment, although this response did not reach the magnitude occurring during normal testicular redevelopment. The decrease in basal prolactin levels observed during treatment was similar to that observed during natural development of testicular function (Wickings \& Nieschlag, 1980a). Full development of exocrine function was not achieved, although the frequencies of both spontaneous and electroejaculation were increased. When ejaculates were obtained, sperm counts were below normal and testicular volumes were still significantly smaller than during the breeding season (Wickings \& Nieschlag, 1980a).

This partial induction of testicular function cannot, however, be attributed to any overstimulation of the pituitary, with resulting down-regulation of the testicular receptors, 
because the acute stimulation tests with the agonist during treatment did not reveal any suppression of pituitary or testicular function. Patients with hypogonadotrophic hypogonadism have indeed been shown to be less susceptible to this inhibitory effect of LH-RH agonists than normal subjects (Smith et al., 1979). These authors attributed the only partial success of their treatment regimen with the same LH-RH agonist as used here to a failure to replenish pituitary LH stores. This was also evident in the agonist-treated monkeys, in which the pituitary response to an acute challenge was much lower than that seen during normal redevelopment.

In contrast to the partial success of the agonist treatment, pulsatile administration of LH-RH during the non-breeding season induced full testicular function. Pulsing with LH-RH also resulted in the production of $\mathrm{LH}$ spikes very similar to those seen in rhesus monkeys during the breeding season (Plant, 1980) and in adult Macaca fascicularis (Steiner et al., 1980). Before treatment no variation in the basal concentrations of $\mathrm{LH}$ or testosterone could be identified during a 24-h sampling period. The distribution of the induced $\mathrm{LH}$ and testosterone spikes was very similar to the breeding season pattern, with the highest frequency occurring during the night. This demonstration of a diurnal pattern of LH spiking under constant LH-RH pulsing suggests that the pituitary can modulate its response to a constant hypothalamic stimulus.

Subcutaneous injection of the LH-RH agonist produced a prolonged elevation of LH before values returned to basal values. This pattern of $\mathrm{LH}$ secretion cannot be compared with that seen in normal monkeys during the breeding season (Plant, 1980), and although some stimulation of pituitary-testicular function was evident, this remained incomplete. The induction of intermittent elevations of $\mathrm{LH}$ and testosterone by pulsatile $\mathrm{LH}-\mathrm{RH}$ treatment, mimicking the normal secretion pattern, results in a more effective stimulation of testicular activity in the sexually quiescent rhesus monkey.

These studies were supported by the Deutsche Forschungsgemeinschaft, Bonn. P.Z. was the recipient of a stipend from the Deutscher Akademischer Austauschdienst. We thank Ms A. Gödde and Ms H. Quante for technical assistance and Ms. Ch. Seiler for secretarial help.

\section{References}

Antunes, J.L., Carmel, P.W., Housepian, E.M. \& Ferin, M. (1978) Luteinizing hormone-releasing hormone in human pituitary blood. $J$. Neurosurg. 49, 382387.

Aparicio, N.J., Schwarzstein, L., Turner, E.A., Turner, D., Mancini, R. \& Schally, A.v. (1976) Treatment of idiopathic normogonadotropic oligoasthenospermia with synthetic luteinizing hormone-releasing hormone. Fert. Steril. 27, 549-555.

Carmel, P.W., Araki, S. \& Ferin, M. (1976) Pituitary stalk portal blood collection in rhesus monkeys: evidence for pulsatile release of gonadotropinreleasing hormone (GnRH). Endocrinology 99, 243-248.

Dierschke, D.J., Bhattacharya, A.N., Atkinson, L.E. \& Knobil, E. (1970) Circhoral oscillations of plasma LH levels in the ovariectomized rhesus monkey. Endocrinology 87, 850-853.

Jacobson, R.I., Seyler, L.E., Tamborlane, W.V., Gertner, J.M. \& Genel, M. (1979) Pulsatile subcutaneous nocturnal administration of $\mathrm{GnRH}$ by portable infusion pump in hypogonadotropic hypogonadism: initiation of gonadotropin responsiveness. J. clin. Endocr. Metab. 49, 652-654.

Knobil, E. (1980) Neuroendocrine control of the menstrual cycle. Recent Prog. Horm. Res. 36, 53-88.
Knobil, E., Plant, T.M., Wildt, L., Belchetz, P.E. \& Marshall, G. (1980) Control of the rhesus monkey menstrual cycle: permissive role of hypothalamic gonadotropin-releasing hormone. Science, N.Y. 207, 1371-1373.

Leyendecker, G., Struve, T. \& Plotz, E.J. (1980) Induction of ovulation with chronic intermittent (pulsatile) administration of LH-RH in women with hypothalamic and hyperprolactinemic amenorrhea. Arch. Gynaek. 229, 177-190.

Lincoln, G.A. (1979) Use of a pulsed infusion of luteinizing hormone-releasing hormone to mimic seasonally induced endocrine changes in the ram. $J$. Endocr. 83, 251-260.

Lincoln, G.A. \& Kay, R.N.B. (1979) Effects of season on the secretion of $\mathrm{LH}$ and testosterone in intact and castrated red deer stags (Cervus elaphus). $J$. Reprod. Fert. 55, 75-80.

Lincoln, G.A., Peet, M.J. \& Cunningham, R.A. (1977) Seasonal and circadian changes in the episodic release of follicle-stimulating hormone, luteinizing hormone and testosterone in rams exposed to artificial photoperiods. J. Endocr. 72, 337-349.

Mastroianni, L. \& Manson, W.A. (1963) Collection of monkey semen by ejaculation. Proc. Soc. exp. Biol. Med. 112, 1025-1027. 
Mortimer, C.H., McNelly, A.S., Fisher, R.A., Murray, M.A.F. \& Besser, G.M. (1974) Gonadotrophinreleasing hormone therapy in hypogonadal males with hypothalamic or pituitary dysfunction. Brit. med. J. iv, 617-621.

Naftolin, F., Judd, H.L. \& Yen, S.S.C. (1973) Pulsatile patterns of gonadotropins and testosterone in man: the effects of clomiphene, with and without testosterone added. J. clin. Endocr. Metab. 36, 285-288.

Nieschlag, E. \& Loriaux, D.L. (1972) Radioimmunoassay for plasma testosterone. Z. klin. Chem. klin. Biochem. 10, 164-168.

Plant, T.M. (1980) The neuroendocrine basis of the diurnal variation of testicular testosterone secretion in the adult rhesus monkey (Macaca mulatta). In Testicular Development, Structure and Function, pp. 419-423. Eds A. Steinberger \& E. Steinberger. Raven Press, New York.

Rowe, P.H., Racey, P.A., Lincoln, G.A., Ellwood, M., Lehane, J. \& Shenton, J.C. (1975) The temporal relationship between the secretion of luteinizing hormone and testosterone in man. J. Endocr. 64, 17-26.

Rubin, R.T., Gouin, P.R., Lubin, A., Poland, R.E. \& Pirke, K.M. (1975) Nocturnal increase in plasma testosterone in men: relation to gonadotropins and prolactin. J. clin. Endocr. Metab. 40, 1027-1033.

Sandow, J., von Rechenberg, W., Baeder, C. \& Engelbart, K. (1980) Antifertility effects of an LH-RH analogue in male rats and dogs. Int. J. Fert. 25, 213-221.
Smith, R., Donald, R.A., Espiner, E.A. \& Stronach, S. (1979) The effects of prolonged administration of D-Ser(TBU) ${ }^{6}$-LH-RH-EA ${ }^{10}$ (HOE 766) in subjects with hypogonadotrophic hypogonadism. Clin. Endocr. 11, 553-559.

Steiner, R., Peterson, A., Yu, J., Conner, H., Gilbert, M. \& Bremner, W. (1980) Circadian and ultradian rhythms of blood testosterone and LH levels in the adult male monkey. Proc. 6th Int. Congress of Endocrinology, Melbourne, Abstr. No. 692.

Wickings, E.J. \& Nieschlag, E. (1980a) Seasonality in endocrine and exocrine testicular function of the adult rhesus monkey (Macaca mulatta) maintained in a controlled laboratory environment. Int. $J$. Androl. 3, 87-104.

Wickings, E.J. \& Nieschlag, E. (1980b) Pituitary response to LRH and TRH stimulation and peripheral steroid hormones in conscious and anaesthetized adult male rhesus monkeys (Macaca mulatta). Acta endocr., Copenh. 93, 287-293.

Wickings, E.J., Qazi, M.H. \& Nieschlag, E. (1979) Determination of biologically active LH in the serum of male rhesus monkey (Macaca mulatta). $J$. Reprod. Fert. 57, 497-504.

Wildt, L., Marshall, G. \& Knobil, E. (1980) Experimental induction of puberty in the infantile female rhesus monkey. Science, N.Y. 207, 1373-1375.

Yen, S.S.C., Tsai, C.C., Naftolin, F., Vandenberg, G. \& Ajabor, L. (1972) Pulsatile patterns of gonadotropin release in subjects with and without ovarian function. J. clin. Endocr. Metab. 34, 671-675.

Received 10 November 1980 